\title{
LA ACCIÓN PÚBLICA DE INCONSTITUCIONALIDAD: A PROPóSITO DE LOS 100 AÑOS DE SU VIGENCIA EN COLOMBIA*
}

\author{
CONSTITUTIONAL ACTION: ON ITS 100TH \\ ANNIVERSARY OF VALIDITY IN COLOMBIA
}

David Mendieta González**

Fecha de recepción: 2 de septiembre de 2009 Fecha de aceptación: 2 de marzo de 2010

* El presente trabajo es un resumen de uno de mayor extensión que fue presentado y aprobado en la Universidad Complutense de Madrid, obteniendo para el autor el DEA (Diploma de Estudios Avanzados) e hizo parte de los procesos dentro del grupo de investigaciones GISOR.

** Abogado y especialista en Derecho Constitucional de la Universidad de Antioquia, candidato a Doctor en Estudios Superiores de Derecho Constitucional de la Universidad Complutense de Madrid, actualmente se desempeña como docente de tiempo completo de la Universidad de Medellín, Colombia. Correo electrónico:dmendieta@udem.edu.co 


\section{RESUMEN}

La acción pública de inconstitucionalidad está próxima a cumplir cien años de existencia ininterrumpida en Colombia, lo que significa que en nuestro país estábamos haciendo control de constitucionalidad abstracto diez años antes de que se creara el Tribunal Constitucional austríaco y diecinueve antes de que KeLSEN propusiera su teoría del legislador negativo. De estos dos últimos hechos mucho se ha dicho a nivel internacional, pero no se ha reconocido al derecho constitucional colombiano como pionero de este tipo de control. Desde los inicios de nuestro constitucionalismo han existido mecanismos de participación directa de los ciudadanos frente a actos emanados de los poderes públicos, mecanismos que se han fortalecido o debilitado según el momento histórico por el que atravesemos. Algo diferente ocurrió en Europa, donde históricamente el control político no es realizado por los ciudadanos sino por sus representantes. La ortodoxia del viejo continente no acepta la acción pública de inconstitucionalidad como un mecanismo válido para evitar el abuso del poder, con el argumento de que esto significaría una gran congestión del tribunal constitucional. Pero en América esta figura se alza como una herramienta de protección de las minorías e individuos frente a los poderes Ejecutivo y Legislativo.

Palabras clave autor: derecho constitucional, constitución, acción de inconstitucionalidad, control de constitucionalidad, Corte Constitucional.

Palabras clave descriptor: Derecho constitucional, corte constitucional, control de constitucionalidad.

\section{ABSTRACT}

The citizen action of unconstitutionality in Colombia is going to be one hundred years of uninterrupted validity. It means that in this country there were on abstracted control of constitutionality ten years before of the creation of the Austrian Constitutional Court and nineteen years before Kelsen created his theory of negative legislator. About the two latest, these have been a lot of discussions in the international field of laws but the Colombian constitutionalism has not been recognized as a pioneer in this field. From the beginning of the Colombian constitutionalism there have been mechanism of direct citizen participation towards acts emanated from the public powers which have been strengthened on weakened according to the historic time is going on. A different case has occurred in Europe where historically the politic control is not done by the citizens but their representants.

The orthodoxy of the European continent does not accept the public action of unconstitutionality as a mechanism valid to avoid the abuse of power argued the constitutional court's collapse. On the other hand in America, this figure raises as institution to protect the individual and minorities rights against the power presidents and parlaments.

Key words: constitutional law, constitutions, action of unconstitutionality, control of constitutionality, Constitutional Court.

Key words plus: Constitutional Law, Colombia, Constitutional Court, Control of constitutionality. 


\section{INTRODUCCIón}

Durante nuestra historia constitucional, la acción pública de inconstitucionalidad tiene antecedentes relevantes que hacen que no sea una figura aislada y, por el contrario, podamos considerarla muy propia de nuestra tradición político-jurídica, de corte rousseauniana ${ }^{1}$, basada en participación directa de los ciudadanos en el naciente Estado.

El desarrollo histórico que hace parte de este documento pretende servir de referente al lector en su proceso de comprensión de la importancia de esta institución en el contexto jurídico nacional e internacional.

El objetivo general del trabajo es estudiar la acción pública de inconstitucionalidad en Colombia, repasando sus orígenes y evolución en el constitucionalismo del país y determinando su sustento actual en la jurisprudencia.

Un estudio de este tipo requiere fundamentos científicos multidisciplinares que abarcan el derecho constitucional, la historia y el derecho comparado.

Las fuentes de investigación utilizadas de acuerdo con la naturaleza del trabajo han sido, primero, el análisis de textos doctrinales de autores clásicos y contemporáneos de la teoría jurídica y constitucional, según queda constancia en las referencias bibliográficas, se han consultado y utilizado un amplio número de autores; segundo, el análisis comparado de diversos textos constitucionales tanto latinoamericanos como europeos; tercero, el estudio de documentos históricos para poder desarrollar el origen y la evolución, hasta nuestros días, de la figura de la acción pública de inconstitucionalidad en Colombia; y cuarto, rastreo de la jurisprudencia de la Corte Constitucional colombiana sobre la materia.

\section{LA ACCIÓN DE INCONSTITUCIONALIDAD EN EL DERECHO COMPARADO: LOS CASOS ITALIANO, ALEMÁN, ESPAÑ்L Y ALGUNOS EJEMPLOS LATINOAMERICANOS}

Algunos países europeos a partir de la Primera Guerra Mundial ${ }^{2}$ acogieron la acción de inconstitucionalidad dentro de su ordenamiento jurídico, pero este proceso se consolidó después del segundo enfrentamiento bélico global con la democratización de los Estados que habían caído bajo el influjo fascista $^{3}$. Posteriormente se extendió a Latinoamérica a medida que se fueron superando las diferentes dictaduras del siglo XX.

1 JuAn JaCOBo Rousseau. Discurso sobre el origen y los fundamentos de la desigualdad entre los hombres. Editorial Alianza. Madrid. (1998) y Del contrato social. Editorial Alianza. Madrid. (1998).

2 Para estudiar el proceso histórico europeo ver: Pedro CRUZ Villalón. La formación del sistema europeo de control de constitucionalidad (1918-1939). CEC. Madrid. (1987).

3 "Parece que ningún país europeo que salga de alguna forma de gobierno no democrático o de una tensión interna importante pueda encontrar mejor respuesta a la exigencia de reaccionar contra de- 
La acción de inconstitucionalidad es la posibilidad que tienen algunas personas que ostentan una calidad especial de índole política, territorial, ciudadana o popular de acudir ante la autoridad constitucional del Estado, para que ésta determine si una ley, y en algunos casos toda norma con fuerza material de ley, está acorde o no con los preceptos constitucionales y, en caso negativo, para que dicha norma sea declarada inconstitucional para su correspondiente salida del ordenamiento jurídico por carecer de validez jerárquica, sin que necesariamente exista un interés de parte o la aplicación de la norma a un caso concreto, con lo que se establece un control de constitucionalidad abstracto y concentrado. Se trata pues de una acción, aunque en otras latitudes la llamen recurso, diferente del control de constitucionalidad difuso, del concreto y de la llamada cuestión de inconstitucionalidad. ${ }^{4}$

La acción de inconstitucionalidad con las particularidades propias de cada modelo se ha dividido en dos tipos, de acuerdo con quién puede instaurarla: la acción de inconstitucionalidad restringida y la acción de inconstitucionalidad popular. La primera sólo puede ser instaurada por algunas autoridades del Estado; la segunda, por cualquier ciudadano y en otros casos por cualquier persona.

A continuación se exponen algunos ejemplos relevantes de cómo funciona esta institución en varios países y cómo en la mayoría de los casos la legitimación para iniciar la acción es restringida a pocas autoridades, ya sea por razones territoriales, políticas o funcionales ${ }^{5}$, a diferencia del caso colombiano donde es un derecho político de todo ciudadano ${ }^{6}$.

Es importante resaltar que los diferentes casos planteados tienen sus propias particularidades y su mención no significa que sean los únicos.

\section{Modelo italiano}

En el modelo italiano, el gobierno puede cuestionar la constitucionalidad de una ley regional por considerar que se excede en las competencias dadas a las regiones, pero éstas a su vez también pueden acudir ante la Corte en aquellos

monios pasados, y posiblemente para impedir su vuelta, que la de introducir la justicia constitucional en su forma de gobierno”. MAURo CAPelletti. ¿Renegar de Montesquieu?: la expansión y legitimidad de la justicia constitucional. Revista Española de Derecho Constitucional. no 17. Madrid. (1986).

4 Para ver la diferencia entre el recurso de inconstitucionalidad y otros controles constitucionales ver: María Luisa Balaguer C. El recurso de inconstitucionalidad, Págs. 71 y ss. CEPC. Madrid. (2001).

5 Una justificación de por qué la legitimación activa para instaurar la acción de inconstitucionalidad debe ser restringida a sólo algunas autoridades, la da JAVIER Pérez Royo: "Justamente por eso, la legitimación para recurrir ante el Tribunal Constitucional se configura de una manera muy restrictiva. Al Tribunal Constitucional no pueden acceder los ciudadanos. Los ciudadanos acceden al poder Judicial, pero no al Tribunal Constitucional. Al Tribunal Constitucional sólo tienen acceso determinados órganos o fracciones de órganos políticos o el poder Judicial". En: Curso de derecho Constitucional. Pág. 140. Ed. Marcial Pons. (2007).

6 Corte Constitucional de Colombia. Sentencia C-536 de 1998. (M.P. José Gregorio Hernández GALINDO). 
casos en los que consideren que una ley de orden estatal o acto con su mismo valor invaden una o varias de sus competencias, en ambos casos establece el término perentorio de sesenta días para impugnar la norma, la acción de inconstitucionalidad italiana cumple claramente una función territorial ${ }^{7}$.

\section{Modelo alemán}

En Alemania el Tribunal Constitucional está facultado para revisar si una norma de menor jerarquía está acorde o no con la Constitución alemana. Esta posibilidad se encuentra consagrada en el artículo 93 , numeral $2^{\circ}$, es el llamado Abstrakte Normenkontrolle. Es un control abstracto, pues el análisis de constitucionalidad no se realiza sobre los efectos de la aplicación de una norma a un caso concreto.

Todas las normas son susceptibles de este control de constitucionalidad, ya sean federales o de los Länder, vigentes antes o después de la expedición de la ley fundamental de Bonn. Puede incluso existir control de constitucionalidad previo, es el caso de las leyes de aprobación de tratados internacionales que, según ha dicho el Tribunal Constitucional, se realiza con el propósito de evitar que se genere responsabilidad internacional del Estado alemán en una posible declaratoria de inconstitucionalidad de un tratado internacional.

Si la norma cuestionada es federal, el referente será la Constitución, pero si es una norma de uno de los Länder, entonces deberá cumplir con los preceptos constitucionales y el resto de normas federales.

En Alemania la legitimación activa obedece a criterios territoriales y de protección a minorías parlamentarias, pues pueden hacer uso de la acción el gobierno federal y el gobierno de cada uno de los Länder y un tercio de los parlamentarios del Bundestag o cámara baja y le es negada esta posibilidad a los miembros de la cámara alta o Bundesrat. ${ }^{8}$

El gobierno federal, el de los Länder y los miembros de la cámara baja en el porcentaje exigido, no están sujetos a iniciar la acción dentro de un plazo perentorio, lo que le da en Alemania cierto dinamismo a la figura.

En el caso alemán la legitimación se otorga sólo a determinados órganos políticos y/o territoriales, como es característica general desde KeLSEN de los sistemas de control concentrado de constitucionalidad, en contraste con lo que ocurre en Colombia, donde está legitimado cualquier ciudadano, constituyéndose en un derecho político, que no está dado a ninguna autoridad por razones territoriales, políticas o funcionales.

Sin embargo, en el Land de Baviera, existe una situación particular, pues allí se consagra una acción de inconstitucionalidad popular en la que la legiti-

7 Constitución de la República Italiana. Art. 127.

8 Ley Fundamental de la República Federal de Alemania. Art. 93, nº 2. 
mación y el interés pertenecen al pueblo. Por lo tanto, cualquier persona está facultada para instaurar la acción sin requerir un interés concreto, directo, personal o que se le haya causado lesión o perjuicio alguno?

\section{Modelo español}

El modelo español de legitimación para el control abstracto de constitucionalidad se aproxima bastante al alemán que, a su vez, sigue de cerca el modelo italiano. La institución del recurso de inconstitucionalidad está consagrada en los artículos 161-1 y 162-1, de la Constitución española de 1978.

En España se le da el nombre de recurso de inconstitucionalidad, a pesar de no existir un proceso previo y están legitimados para instaurarlo: el presidente del gobierno y los órganos legislativos y ejecutivos autonómicos, las minorías parlamentarias (50 diputados y 50 senadores) y el defensor del pueblo; esta es tal vez una de las particularidades más destacadas de este sistema ${ }^{10}$.

España ha sido el primer país en donde se ha legitimado al defensor del pueblo $^{l l}$ para interponer el recurso de inconstitucionalidad y su ejemplo ha sido seguido por varios países europeos y latinoamericanos, atribuyéndole a su ombudsman (defensor del pueblo) la legitimación para impugnar directamente la constitucionalidad de las leyes. Es el caso, por ejemplo, de Polonia o Ucrania, en el viejo continente; y en América tenemos como ejemplos la Constitución guatemalteca de 1985, la peruana de 1993, la ecuatoriana de 1998 o la venezolana de $1999^{12}$.

Esta posibilidad acercaría el modelo español a una acción popular, por la afinidad teórica y competencial de este funcionario con el pueblo; sin embargo, esto no se ha materializado, haciendo del caso español mucho más compatible al modelo de legitimación restringida, a pesar de ello es más amplio que el italiano o el alemán.

En la praxis el papel del defensor del pueblo español en los recursos de inconstitucionalidad ha sido discreto. Su actuación más comprometida la constituyó probablemente el recurso de inconstitucionalidad contra la Ley 48 de 1984, reguladora de la objeción de conciencia y la prestación social

9 Constitución de Baviera. Art. 98.4: "todo habitante de Baviera que se sienta lesionado en sus derechos constitucionales por un poder público, puede reclamar la protección del tribunal constitucional bávaro".

10 Para estudiar más a fondo la figura del recurso de inconstitucionalidad en España ver: MARÍA Luisa Balaguer C. El recurso de inconstitucionalidad. CEPC. Madrid. (2001); Asunción García MARTínEz. El recurso de inconstitucionalidad: el proceso directo de inconstitucionalidad. Ed. Trivium S.A. Madrid. (1992). entre otros.

11 Su legitimación constitucional es ratificada en la LO 3/81.

12 Ver: Joaquín Camazano Brage. La acción abstracta de inconstitucionalidad. Pág. 172. Primera edición. Universidad Autónoma de México, Ciudad de México. (2005). 
sustitutoria, en la que el Tribunal Constitucional dictó la Sentencia 160 de 1987, desestimatoria del recurso.

El ombudsman (defensor del pueblo) español podría tener un papel protagónico en calidad de garante del pueblo y su derecho a la Constitución de 1978 , en aquellos casos en que una ley u otra norma con fuerza material de ley la contraríen, aunque, es un camino poco explorado en España ${ }^{13 .}$

\section{Algunos modelos latinoamericanos}

En América Latina, muchos países han instaurado el sistema de control de constitucionalidad abstracto, ya sea de tipo restringido o popular. Con carácter restringido tenemos el caso de Perú, donde existen varias autoridades legitimadas para instaurar la acción e incluso el pueblo en un número plu$\mathrm{ra}^{14}$. En México la figura es reciente, aunque la Constitución mexicana data de 1917, sólo se estableció esta forma de control constitucional a partir de la reforma constitucional de 1994, la cual fue adicionada mediante las reformas constitucionales de 1996 y del $2006^{15}$; en Brasil se faculta al Supremo Tribunal Federal, en los términos de los artículos 102 y 103, en calidad de garante de la Constitución de la República Federativa del Brasil, expedida en 1988, para conocer las acciones de inconstitucionalidad ${ }^{16}$.

Además de Colombia, en América Latina otros países han legitimado al ciudadano para instaurar acciones de inconstitucionalidad ante el Tribunal Constitucional o sala de constitucionalidad, según el caso, así sucede en El Salvador ${ }^{17}$, Nicaragua ${ }^{18}$, Ecuador ${ }^{19}$, que en su Constitución del 2008 prevé la posibilidad de que cualquier ciudadano o ciudadana, de manera individual o colectiva, pueda instaurar este tipo de acción; y más recientemente Bolivia, que conforme a la Constitución del 2009 amplía la posibilidad de demandar cualquier norma a toda persona individual o colectiva ${ }^{20}$.

13 Valoración hecha por: María Luisa Balaguer C. El recurso de inconstitucionalidad. Pág. 81 y ss. CEPC. Madrid. (2001).

14 Constitución peruana. Art. 203.

15 Constitución de los Estados Unidos de México de 1917, para ver más particularidades e inconvenientes del modelo mexicano ver: Joaquín Brage CAMAzano. En "La acción mexicana de inconstitucionalidad en el marco del derecho comparado: regulación actual y posibles líneas de evolución". Trabajo publicado en Revista Iberoamericana de Derecho Procesal Constitucional. Proceso y Constitución, número 3, Porrúa, México, enero-junio (2005).

16 Constitución de la República Federativa del Brasil. Arts. 102 y 103.

17 Constitución de la República de El Salvador de 1983. Art. 172.

18 Constitución de la República de Nicaragua de 1987. Art. 187.

19 Constitución Política del Ecuador 2008. Art. 441.

20 Constitución de la República de Bolivia del 2009. Art. 132. 
En Venezuela ${ }^{21}$ y Panamá ${ }^{22}$ se va más allá, en cuanto se reconoce legitimación a cualquier persona natural o jurídica, nacional o extranjera o incluso, que no tenga la edad necesaria para ejercer sus derechos políticos.

En Guatemala ${ }^{23}$ se reconoce legitimación también a cualquier persona, pero sólo con el auxilio de tres abogados colegiados activos. En Uruguay ${ }^{24}$, Honduras ${ }^{25}$ y Paraguay ${ }^{26}$ se exige en cambio un interés personal, legítimo y directo frente a una situación concreta, para que cualquier persona pueda impugnar la constitucionalidad de una norma.

En Chile ${ }^{27}$, una reciente reforma ha establecido la acción de inconstitucionalidad ante el Tribunal Constitucional, siempre y cuando el mismo Tribunal haya declarado la inaplicación de la norma, en un análisis de constitucionalidad previo.

\section{LA ACCIÓN DE INCONSTITUCIONALIDAD EN COLOMBIA}

La historia de Colombia está marcada por la violencia y el sectarismo. Los actores políticos han convertido los textos constitucionales en trofeos de guerra, los ganadores, ya sea por vías de derecho o de hecho, han encontrado en la expedición de nuevas constituciones o en grandes reformas constitucionales la manera de mostrarles a sus enemigos sus triunfos y la herramienta para perpetuarse en el poder ${ }^{28}$.

Pensar que la Constitución es la culpable de nuestras vicisitudes ha sido de arraigo en el devenir histórico colombiano. Un nuevo texto constitucional o una gran reforma han sido las soluciones simplistas a nuestros males, soluciones que ignoran la problemática de fondo: la injusticia social, la corrupción y el dogmatismo político, entre otros factores.

Durante la historia constitucional colombiana a muchos se les ha encargado el control constitucional, unas veces al legislador, otras al poder Ejecutivo o al Judicial, controles eclécticos, mixtos, entre otros. Existe no obstante una institución en nuestro ordenamiento jurídico que vale la pena estudiar detenidamente y es la acción pública de inconstitucionalidad. Hernando

21 En Venezuela la acción de inconstitucionalidad está abierta a cualquier persona sin necesidad de invocar un interés especial y está exenta de plazos de caducidad en los términos de los artículos 334, 335 y 336 de la Constitución de la República Bolivariana de Venezuela de 1999.

22 Constitución de la República de Panamá de 1972. Art. 203.

23 Constitución de la República de Guatemala de 1985. Art. 267.

24 Constitución uruguaya. Art. 258.

25 Constitución de la República de Honduras de 1982. Art. 184.

26 Constitución de la República del Paraguay de 1992. Art. 260.

27 Constitución de la República de Chile de 1980, reformada en 2005. Art. 93.

28 "Cada una de las constituciones del siglo XIX fue la consecuencia de una guerra y la causa de otra. Cada una de las reformas del siglo XX ha sido consecuencia de un conflicto y causa de otro". Hernando Valencia Villa. Cartas de batalla: una crítica al constitucionalismo colombiano. Pág. 149. Fondo Editorial CEREC. Segunda Edición. (1997). 
Valencia Villa al referirse a esta forma de control de constitucionalidad dice que es probablemente la única contribución significativa del derecho colombiano al derecho occidental. ${ }^{29}$

La acción pública de inconstitucionalidad que hoy tenemos en Colombia, con escasos cambios, data de 1910; sin embargo, la posibilidad de que un ciudadano pudiese acudir ante una autoridad para demandar una norma por ser contraria a la Constitución, no ha sido ajena a la historia constitucional del país, incluso en fechas anteriores a la ya mencionada.

La necesidad del control de constitucionalidad de las leyes y demás normas con fuerza material de ley surge en Colombia con la idea misma de Constitución. Ya el texto constitucional de Cundinamarca de 1811, para muchos la primera constitución de la América hispánica ${ }^{30}$, permitía a cualquier ciudadano hacer uso de una institución que algunos tratadistas como CARLos RESTREPO PIEDRAhÍta han llamado "acción popular"

La constitución del Estado de Cartagena de Indias, del 14 de junio de 1812, también les reconoció a los ciudadanos la acción popular. La segunda constitución de Cundinamarca de 1812, en su artículo 62, título IV, permitía a cualquier ciudadano elevar su queja ante el Senado conservador (que era el encargado de velar por la Constitución) en caso de que alguno de los tres poderes o alguno de sus miembros quebrantara notoriamente algún artículo constitucional.

El siguiente ejemplo de una institución con las características de la acción pública de inconstitucionalidad lo encontramos en la Constitución de 1853, que en su artículo 42, al referirse a las competencias de la Corte Suprema de Justicia, establecía la obligación de esta corporación de decidir la nulidad de las ordenanzas municipales en caso de ser contrarias a la Constitución o a las leyes de la República. En este mismo año, en la provincia de Santander fue expedida una constitución que en su artículo 55 establecía la posibilidad de que cualquier habitante de la provincia, funcionario público o interesado, pudiera pedir la anulación de las ordenanzas provinciales y de los acuerdos de los cabildos por contradecir los preceptos constitucionales ${ }^{32}$.

29 Ibíd. Pág. 46.

30 Uprimny, Leopoldo. "Verfassungsgerichtsbarkeit in Kolumbien". Estudio presentado al coloquio internacional convocado por el instituto Max Planck para derecho y derecho internacional de extranjeros, incluido en el volumen colectivo Verfassungsgerichtsbarkeit in der Gegenwart, Heidelberg, 1962, Heymanns Verlag KG, Köln- Berlín. Dice Uprimny: "La Constitución del "Estado" de Cundinamarca fue la primera constitución de la antigua América española".

31 "Habrá un Senado de censura y protección, compuesto de un presidente, que lo será el vicepresidente de la representación nacional, y cuatro miembros, para sostener esta Constitución y los derechos del pueblo, a fin de que de oficio o requerido por cualquier ciudadano, reclame cualquiera infracción o usurpación de todos o cada uno de los tres poderes Ejecutivo, Legislativo y Judicial que sea contra el tenor de la Constitución" (art. $9^{\circ}$ del título I). Carlos Restrepo Piedrahíta. Tres ideas constitucionales. Pág. 17. Ediciones Universidad Externado de Colombia. (1978).

32 "Cualquier funcionario o habitante de la provincia, o interesado de fuera de ella, tiene derecho de pedir ante el respectivo tribunal de distrito la anulación de todas o de parte de las ordenanzas 
La Constitución de los Estados Unidos de Colombia de 1863, en el artículo $72^{33}$, previó la posibilidad de suspensión y anulación de actos de los estados federados por ser contrarios a ella, a petición de cualquier ciudadano o del procurador general, correspondía a la Corte Suprema Federal suspender el acto e informar al Senado para que éste determinara su anulación o no. ${ }^{34}$

La Constitución regeneracionista de 1886 no estableció la acción pública de inconstitucionalidad y dejó el control de constitucionalidad en manos de la Corte Suprema de Justicia, pero sólo a petición presidencial por vía de objeción de un proyecto de ley, lo que significaba que no existía un control de constitucionalidad posterior a las leyes, esto era herencia de la creencia francesa de la bondad y perfección de la ley, por ser emanación directa del legislador, quien a su vez representaba los intereses del pueblo.

Durante esta época se dieron fuertes enfrentamientos entre los defensores de la supremacía de la Constitución y quienes avalaban la perfección de la ley. Muestra de esto es la expedición en 1887 de dos leyes opuestas, la 5735, que reforzó la idea de supremacía constitucional y la $153^{36}$, que expresamente consagró la supremacía de la ley, sobre la Constitución. Basándose en esta última ley, la misma Corte Suprema declaró su falta de competencia en la revisión de la constitucionalidad de las leyes ${ }^{37}$ La supremacía de la Constitución daba paso a la primacía de la ley.

Sin embargo, muchos reclamaban regresar a la supremacía constitucional, es el caso de Felipe Paúl, quien era uno de los juristas más influyentes del país, había participado en el Consejo Nacional Constituyente de 1885 y en

provinciales, por ser opuestas a esta Constitución, i de los acuerdos de los cabildos, cuando sean opuestos a la Constitución o las leyes de la República, o la Constitución u ordenanzas provinciales". Constitución de la provincia de Santander de 1853. Art. 55.

33 "Corresponde a la Corte Suprema suspender, por unanimidad de votos, a pedimento del procurador general o de cualquier ciudadano, la ejecución de los actos legislativos de las asambleas de los estados, en cuanto sean contrarios a la Constitución o a las leyes de la Unión, dando, en todo caso, cuenta al Senado para que éste decida definitivamente sobre la validez o nulidad de dichos actos". Constitución de los Estados Unidos de Colombia, 1863. Art. 72.

34 Laureano Gómez Serrano. El control de constitucionalidad en Colombia: evolución histórica. Pág. 105. Ediciones Doctrina y Ley. (2007).

35 "Artículo $5^{\circ}-$ Cuando haya incompatibilidad entre una disposición constitucional y una legal, preferirá aquella". Ley 57 de 1887.

36 "Artículo $6^{\circ}$-Una disposición expresa de ley posterior a la Constitución se reputa constitucional, y se aplicará aun cuando parezca contraria a la Constitución”. Ley 153 de 1887. Este artículo fue derogado por el acto legislativo 03 de 1910, que encaminó al país por la senda del constitucionalismo garantista.

37 "La Corte no puede acogerse a este argumento, y se funda para ello en que al poder Judicial no le está atribuida la interpretación general y auténtica de la Constitución o de las leyes sustantivas, ni le es permitido dejar de observar estas porque las juzgue contrarias a la Constitución".

"No está establecido en la República ningún tribunal o autoridad que tenga la facultad de declarar que una ley deja de ser obligatoria por ser contraria a un precepto constitucional".

"Al contrario, el artículo $6^{\circ}$ de la Ley 153 antes mencionada, dice que una disposición expresa de la ley posterior a la Constitución se reputa constitucional y se aplicará aun cuando parezca contraria a la Constitución...”. Corte Suprema de Justicia, Gaceta Judicial, número 155, año III, septiembre 28 de 1889, pág. 403. 
su momento manifestó la necesidad de proteger al individuo de los poderes Legislativo y Ejecutivo. ${ }^{38}$

JuAn C. ArbelÁez, en calidad de representante a la Cámara, presentó ante esta corporación en 1894, un proyecto de ley que establecía un control de constitucionalidad de las leyes compartido entre la Corte Suprema de Justicia, con carácter suspensivo y el Congreso de la República con carácter definitivo, legitimando para instaurar la acción a todo colombiano varón, mayor de edad y a las personas jurídicas ${ }^{39}$, pero el proyecto no fue aprobado.

En la ciudad de Medellín, en 1904, una reunión bipartidista llamada Junta de Conciliación de Antioquia, que buscaba restablecer la unidad de los colombianos luego de las guerras civiles de 1895 y la de los Mil Días (1899-1902) y la dolorosa separación de Panamá. Esta junta propuso sin éxito organizar los poderes públicos para asegurar su independencia y hacer de la Corte Suprema de Justicia juez de constitucionalidad de las leyes, a petición del ministerio público o de cualquier ciudadano. ${ }^{40}$

Frente a los abusos que venía cometiendo el Ejecutivo a través del estado de sitio, el Congreso aprobó la Ley $2^{\mathrm{a}}$ de $1904^{41}$, que establecía el control de constitucionalidad de los decretos de estado de excepción, a petición del procurador general de la Nación o de cualquier ciudadano, pero la vigencia de dicha acción pública fue efímera, pues fue derogada tan sólo un año después. El país estaba ya en presencia de su primer dictador militar del siglo XX,

38 "Pues bien, con el transcurso del tiempo... se pensará en reformar la Constitución en el sentido de establecer un alto tribunal que decida de los casos de inconstitucionalidad de una ley, cuando ella no haya sido objetada por el Gobierno, y entonces se atribuirá a la Corte Suprema, como sucede en los Estados Unidos de Norteamérica, la delicada función de amparar al individuo contra los poderes Legislativo y Ejecutivo... los que estamos viejos, fatigados, no veremos esto, pero de esta reforma disfrutarán nuestros hijos". Anales de la Cámara de Representantes, nº 6, del 13 de agosto de 1894.

39 "Artículo $1^{\circ}-$ Los colombianos varones y mayores de edad y las personas jurídicas pueden denunciar ante la Corte Suprema de Justicia las leyes nacionales que estimen inconstitucionales.

La denuncia se hará por escrito y se expresarán en él las razones por las que se estima que la ley denunciada es inconstitucional."

"Artículo $6^{\circ}$-La Corte resolverá sobre la inconstitucionalidad de la ley denunciada, dentro de los 20 días después de la audiencia.

Si declara que la ley es inconstitucional, se suspenderá su cumplimiento. De la resolución de la Corte se dará cuenta a la siguiente legislatura en que el personal de la Cámara de Representantes se haya renovado; y si el Congreso declarase, en un solo debate en cada Cámara, que considera constitucional la ley, esta se observará." Anales de la Cámara de Representantes, $\mathrm{n}^{\circ}$ 17, del 25 de agosto de 1894. Pág. 132.

40 "Organizar los poderes públicos, guardando la independencia y separación recíproca entre ellos; y hacer a la Corte Suprema de Justicia árbitro e intérprete de la inteligencia y constitucionalidad de las leyes a pedimento del ministerio público o de los ciudadanos". Carlos E. Restrepo. Texto de orientación republicana. Tomo I. Sin fecha. Pág. 176.

41 "Artículo $2^{\circ}-$ La Corte Suprema de Justicia a solicitud de cualquier ciudadano y previa audiencia del procurador general de la Nación, decidirá definitivamente, en sala de acuerdo sobre la validez o nulidad de los decretos legislativos, de conformidad con el artículo anterior y con lo dispuesto en la Constitución Nacional en la materia". Ley $2^{\mathrm{a}}$ de 1904. 
Rafael Reyes, quien llevó con mano fuerte las riendas del país entre 1904 y 1909 y, además, manipuló la Constitución a su conveniencia.

En 1910 se realizó una de las reformas constitucionales más importantes en la historia de Colombia, gracias a un movimiento político denominado Unión Republicana, liderado por Carlos E. Restrepo que buscaba sacar al país de la lucha bipartidista e implementar una Constitución verdaderamente nacional e incluyente y no el trofeo de guerra de un bando victorioso como había sucedido con la Constitución de 1863 y el triunfo del radicalismo liberal o la de 1886 y la llegada al poder de la regeneración conservadora, lo anterior precisamente en una época en la que se celebraba el centenario de nuestra independencia.

Con la expedición del Acto Legislativo 3 del 31 de octubre de 1910, se buscó sacar al país del autoritarismo de la Constitución de 1886, que junto con el legislador de entonces, habían facilitado la implantación de un gobierno dictatorial, el llamado "Quinquenio de Reyes". Es importante resaltar cómo los abusos de una dictadura nos regresaron a la senda del constitucionalismo.

La reforma constitucional de 1910 es de suma importancia no sólo en Colombia sino también en el mundo, pues establece la posibilidad de que un tribunal saque del ordenamiento jurídico una ley o un decreto del gobierno por ser contrarios a la Constitución, lo anterior por petición ciudadana. Es decir, ya para 1910, la Corte Suprema de Justicia de Colombia obraba como legislador negativo, ${ }^{42} 10$ años antes de que se creara el Tribunal Constitucional austríaco y 19 años antes de que KELSEN expusiera su teoría sobre el tema.

Continuando con la evolución histórica de la institución de la acción pública de inconstitucionalidad en Colombia, en 1941 se expidió la Ley 167 o Código Contencioso Administrativo, que en su artículo 62 intentó dividir el control de constitucionalidad de las normas entre la Corte Suprema de Justicia y el Consejo de Estado; sin embargo, este artículo fue declarado inexequible por la misma Corte mediante sentencia del 7 de julio de 1942. En este sentido una nueva reforma se expidió en 1945 mediante el Acto Legislativo 1. Esta reforma repartió competencia en materia de control de constitucionalidad dándole a la Corte Suprema de Justicia el control de los actos reformatorios de la Constitución, de las leyes, de los decretos del Ejecutivo con fuerza de ley y de los proyectos de ley objetados por el presidente por inconstitucionales e insistidos por el Congreso de la República; y a la jurisdicción contencioso administrativa, con el Consejo de Estado a la cabeza, le correspondió teniendo en cuenta los factores de reparto: los decretos que no fueran competencia de la Corte Suprema, las ordenanzas departamentales, los acuerdos municipales y las resoluciones de los entes administrativos.

42 Hans Kelsen. ¿Quién debe ser el defensor de la Constitución? Pág. 37. Editorial Tecnos. Madrid. (1993). $3^{\text {a }}$ edición, la primera edición en alemán es de 1929. 
Con lo anterior, no solo se estableció la acción pública de inconstitucionalidad de los actos reformatorios de la Constitución, las leyes y normas con fuerza de ley, sino que dicha acción se amplió a todas las normas jurídicas con rango infralegal, pero en estos casos se denominó acción de nulidad por inconstitucionalidad.

En 1953, el gobernante del partido conservador, amparado por el estado de sitio (estado de excepción establecido en la Constitución de 1886), quiso recuperar el orden público exaltado luego del bogotazo, y buscó alterar la Constitución convocando una comisión de estudiosos constitucionales seleccionados entre sus afines, esta comisión propuso una reforma constitucional en la que se pretendía suprimir el control de constitucionalidad de las leyes y decretos del Gobierno con fuerza de ley, aduciendo que el control de constitucionalidad de las leyes por parte de la Corte Suprema de Justicia era una forma de desnaturalizar la justicia y politizarla. ${ }^{43}$

La propuesta no se materializó porque el 13 de junio de 1953, el presidente Laureano Gómez Castro fue depuesto por la segunda y última dictadura militar del siglo XX en Colombia, la de Gustavo Rojas Pinilla.

La acción pública de inconstitucionalidad fue novedosa cuando fue creada en 1910, pero 40 años después pocos resultados había dado, se criticaba su lentitud, la Corte Suprema de Justicia tardaba años y hasta décadas en pronunciarse sobre la constitucionalidad de una ley o norma con fuerza de ley, muchas veces el fallo fue inhibitorio, pues a la hora de fallar la norma ya había sido derogada tiempo atrás. Sobre este asunto en particular CARLOS Restrepo Piedrahíta hizo un análisis que nos permite observar cómo esta forma de control normativo se convirtió en Colombia, a mediados del siglo $\mathrm{XX}$, en una institución inerte y de mínimos alcances ${ }^{44}$.

43 "Eliminamos de la jurisdicción de la Corte Suprema la guarda de la Constitución porque la experiencia ha demostrado que las contiendas sobre temas constitucionales provocadas en el más alto tribunal, llevan consigo la pasión política partidaria y justamente es propósito fundamental de ésta reformar y liberar la administración de justicia de todo cuanto pueda desnaturizarla, entorpecerla y desviarla". Comisión de Estudios Constitucionales. Proyecto de Reforma; Estudios constitucionales. Págs. 403 y ss. Bogotá. Tomo II. (1953).

44 "No obstante la trascendencia teórica que representa el establecimiento de un instituto de jurisdicción constitucional tan amplio como el de 1910, del cual debería esperarse progresos muy significativos para el desarrollo del régimen jurídico colombiano y de la ciencia jurídica -sentimiento del derecho, Rechtsgefühl-del pueblo, tales expectativas no se satisficieron en forma apreciable. La acción popular fue - y sigue siendo-apenas saltuariamente utilizada por los ciudadanos y la Corte Suprema se comportaba displicentemente morosa para decidir las demandas de inexequibilidad. Tal situación anómala dio lugar a que el dictador Rojas Pinilla, con propósitos hipócritas, pero respaldado por evidencias, públicamente le increpara a la Corte su falta de diligencia. En carta a juristas de Medellín, con fecha del 4 de septiembre de 1956, decía "Es posible que muchos de ustedes ignoren que en la honorable Corte Suprema de Justicia cursan actualmente 35 demandas de inexequibilidad y que hay asuntos de esta índole que hace diez años esperan su solución definitiva. Con razón se promovió el año pasado un movimiento de opinión pública, dirigido por los órganos de prensa y por notables ciudadanos, entre los cuales se contaban muchos de ustedes, encaminado a pedirle a la Corte que no postergara más su pronunciamiento sobre las demandas de inconstitu- 
En 1957 es derrocado Rojas Pinilla quien decide exiliarse y el poder lo asume una junta militar. Los partidos políticos pactan el llamado Frente Nacional en el que el aparato burocrático estatal es repartido por partes iguales entre liberales y conservadores, quienes además se alternaron el cargo presidencial, primero por un período de doce años, que luego fue aumentado a dieciséis. En el país se seguían enfrentando hermanos contra hermanos, pero a los líderes políticos sólo se les ocurrió atacar el problema en apariencia, en el fondo las causas de la violencia seguían insolutas.

Durante la década de los sesenta, pequeños grupos de autodefensas campesinas de origen liberal se convierten en guerrilla al no estar satisfechos y sentirse traicionados por la élite de su partido. Llega entonces otra gran reforma constitucional en 1968 que fortalece aún más nuestro sistema presidencialista, liderada por el segundo presidente liberal del Frente Nacional, Carlos Lleras Restrepo. En dicha reforma se creó la Sala Constitucional de la Corte Suprema de Justicia compuesta por cuatro magistrados especialistas en derecho público, que estaban encargados de proyectar los fallos de los juicios de constitucionalidad y a quienes se les impusieron términos perentorios para hacerlo so pena de incurrir en "causal de mala conducta".

Además, se sustrajo de la acción pública de inconstitucionalidad los decretos de estado de sitio, que pasaron a tener control automático y de oficio por parte de la Corte Suprema de Justicia. Se amplió el control de constitucionalidad de la ley por vicios en el procedimiento de su creación, competencia que hasta entonces la misma Corte había evitado asumir.

Pero no era el único tema en el que el juez de constitucionalidad de las leyes en Colombia se autolimitó, por ejemplo, durante años fue reiterativa su posición de falta de competencia a la hora de conocer de la constitucionalidad de las leyes que ratificaban tratados internacionales, con el argumento de que este era un tema de competencia exclusiva del Ejecutivo.

La misma Corte se convirtió en un obstáculo para el uso efectivo de la acción pública de inconstitucionalidad al exigirle al accionante una serie de requisitos que ni la Constitución ni la ley pedían, pero que, avalados por vía jurisprudencial, fueron convirtiendo esta institución en tema de expertos jurisconsultos y la alejaron de su verdadera vocación que no era otra que permitirle al ciudadano hacer control político efectivo a los actos del legislador y del ejecutivo.

cionalidad que tenía pendientes" (Gaceta Judicial, nº 2171-2172-2173. Tomo LXXXIII, Págs. 421, 422). Catorce años duró en la Corte una demanda que instauró el doctor Luis E. Nieto Arteta contra los decretos 1381 y 1382 de 1940 (V. Gaceta Judicial, no 2150. Tomo LXXIX, Págs. 412 y 413). Tres años la instaurada contra la Ley 56 de 1921. (Gaceta Judicial Tomo LXXXVII..Págs. 8 y ss.) otras demoraron cuatro años". Restrepo Piedrahíta, Carlos. Op. cit. Pág. 65. téngase en cuenta que la obra fue escrita por el autor en 1977. 
El argumento de la ineptitud de la demanda por no haber demandado varias normas, por no precisar las razones de la violación de la Constitución o por hacerlo de manera vaga, le quitó alcance a la acción. Sobre el tema existe reiterada jurisprudencia de la Corte Suprema de Justicia ${ }^{45}$.

Primero la mora de la Corte para expedir sus fallos de constitucionalidad y luego los obstáculos procesales impuestos por ésta en el trámite de declaratoria de inconstitucionalidad alejaron la figura de la acción pública de inconstitucionalidad de su razón de ser: el ciudadano ${ }^{46}$.

Durante décadas, la Corte Suprema de Justicia no ejerció a cabalidad su función de evitar el abuso del poder mediante el control de constitucionalidad, por el contrario, fue cómplice por omisión de extralimitaciones del poder estatal. La Constitución de 1886 perdió cualquier protagonismo, pues su guardián se había negado a defenderla. Colombia no era un Estado democrático y constitucional de derecho, era un Estado de vías de hecho, prueba de lo anterior fue la crisis institucional de la década de los 80 .

En 1991, como consecuencia de un movimiento social y político, a los colombianos se nos presenta un nuevo texto constitucional, que teniendo en cuenta el principio de la supremacía constitucional contenido en el artículo $4^{\circ}$, en sus artículos 40 numeral $6^{\circ}, 241$ y 242 , conserva la acción pública de inconstitucionalidad de 1910 y le entrega la guarda y cuidado de la supremacía e integridad de la Constitución a la Corte Constitucional.

En 1993 hubo un importante pronunciamiento de la Corte Constitucional en lo concerniente a la acción pública de inconstitucionalidad. En la sentencia C-003, con ponencia del doctor Alejandro Martínez Caballero, el máximo tribunal de lo constitucional en Colombia estableció que estaban legitimados

45 "Tal es el caso del libelo que se examina, en el que aparece acusada solamente una (norma), la cual con el inciso primero (de otra norma no acusada), configura una proposición jurídica completa formada por la regla punitiva y su excepción, estrechamente unidas, y tanto que esta conexión resultaría rota de la causa si la Corte procediera a dar un fallo de fondo. Existe pues ineptitud de la demanda de tal naturaleza, que impide resolver el asunto sometido a estudio. Por este motivo el fallo será de carácter inhibitorio". Vid. Gaceta Judicial, Corte Suprema de Justicia, sentencia del 28 de agosto de 1970.

"...indudablemente si se trata de la existencia de una relación de conexidad con la norma acusada, respecto de otras no mentadas en la demanda, saltaría a los ojos el carácter incompleto de la citada proposición; lo mismo en aquellos casos en que la norma demandada, por constituir solamente un aspecto parcial o incompleto de un todo normativo, de un mandato integral del legislador, impide por ello que pueda captarse plenamente su sentido”. Vid. Gaceta Judicial. Corte Suprema de Justicia. Sentencia del 4 de marzo de 1981.

46 "Es indudable que en el curso del siglo XX en Colombia se había estructurado formalmente un sistema pleno de control constitucional, encomendado al poder Judicial, a través de su más alta corporación, lo que debía garantizar su ejercicio con total autonomía en procura de garantizar los derechos fundamentales a todos los ciudadanos. Sin embargo, los vínculos reales de la judicatura con los detentadores del poder le ligaban más con los tentáculos autoritarios que preconizaban por las vías del estado de excepción que con las vertientes del pensamiento democrático, que observaban cómo ella eludía su función fundamental en los estados contemporáneos para enfrascarse en las disputas intestinas por el control de los privilegios, encubriendo su oscilante posición con el ropaje esotérico de las más solemnes jurisprudencias”. Laureano Gómez Serrano. El control de constitucionalidad en Colombia: evolución histórica. Págs. 177 y 178. Ediciones Doctrina y Ley Ltda. Bogotá. (2007). 
para hacer uso de esta institución sólo los ciudadanos, incluso los magistrados de la Corte Constitucional y privó de tal derecho a las personas jurídicas.

Pero a partir de 1999 la Corte Constitucional, como en su época lo hiciera la Corte Suprema de Justicia, ha ido estableciendo requisitos al ciudadano en el ejercicio de su "derecho político" de demandar las leyes u otras normas con fuerza de ley por ser contrarias al texto de la Constitución.

A continuación se revisarán algunas sentencias representativas, que nos permitirán examinar la variación jurisprudencial de la Corte en el tema de los requisitos procesales de la acción pública de inconstitucionalidad.

En la Sentencia C-275 de 1996, con ponencia del doctor José GrEgORIO Hernández Galindo, la Corte Constitucional colombiana, partiendo de lo establecido en varias normas constitucionales, buscó facilitar el acceso a la acción pública de inconstitucionalidad, flexibilizando las exigencias procesales y haciendo prevalecer lo sustancial.

En la sentencia C-536 de 1998, con el mismo ponente, la Corte estableció las razones por las cuales los condenados no pueden hacer uso de la acción pública de inconstitucionalidad, al menos de manera temporal, por tratarse de un derecho político sujeto a la condición indispensable de hallarse en ejercicio de la ciudadanía. Para la Corte Constitucional aquel que sufre la pena de interdicción de derechos y funciones públicas está excluido de esa posibilidad por falta de legitimación del accionante. Lo anterior a pesar de que la Constitución en sus artículos 40 numeral $6^{\circ}$ y 99 , no dice que el ejercicio de la ciudadanía es condición previa para ejercer el derecho a instaurar acciones en defensa de la Constitución.

Entre 1999 y el 2001, la Corte Constitucional profirió los últimos fallos que establecían la formalidad mínima de la acción. A partir del 2001, por el cambio de integrantes de la Corte Constitucional, esta corporación ha mostrado mayor exigencia a la hora de admitir las acciones públicas de inconstitucionalidad. Ejemplo de lo anterior es el fallo inhibitorio proferido en la Sentencia C-652 del 2001, siendo el magistrado ponente el doctor JAIME CóRdOBA TRIviÑo, por considerar que el accionante no expuso los motivos por los cuales un decreto-ley expedido por el Ejecutivo vulneraba la Constitución y exige a la hora de instaurar una acción pública de inconstitucionalidad contra una ley u otra norma con fuerza de ley, que se señalen las normas acusadas como inconstitucionales y su transcripción literal o un ejemplar de la publicación oficial de las mismas; el señalamiento de las normas constitucionales que se consideran infringidas; las razones por las cuales dichos textos se estiman violados; cuando fuere el caso, el señalamiento del trámite impuesto por la Constitución para la expedición del acto demandado, la forma en que fue quebrantado y la razón por la cual la Corte es competente para conocer la demanda, lo anterior conforme a lo establecido en el Decreto 2067 de 1991. La aplicación rigurosa de estos requisitos limita el acceso a la acción, pues 
requiere un conocimiento especializado de temas jurídicos en general y constitucionales en particular, restringiendo su ejercicio, pues no todos los ciudadanos poseen o tienen a su alcance dicho conocimiento.

En la sentencia C-1052 del 2001, siendo el magistrado ponente el doctor Manuel José Cepeda Espinosa, la Corte fijó requisitos de procedibilidad en el ejercicio de la acción pública de inconstitucionalidad que no fueron fijados ni por el constituyente, ni por el legislador y así, partiendo del artículo $2^{\circ}$ del Decreto 2067 de 1991, hizo una interpretación extensiva del mismo.

Dice la Corte que el ciudadano que ejerce la acción pública de inconstitucionalidad debe aportar los siguientes elementos:

1. Identificar el objeto sobre el que versa la acusación, lo que significa señalar las normas que se consideran inconstitucionales, además, se exige su transcripción literal por cualquier medio.

2. El concepto de la violación, esto implica que el ciudadano debe señalar las normas constitucionales que se consideran infringidas, debe manifestar además cuáles elementos materiales relevantes de la Constitución resultan vulnerados por la norma cuestionada. Aclara la Corte que no basta con que el accionante se limite a transcribir la norma constitucional. Con esta exigencia del tribunal se corre el riesgo de que la acción de inconstitucionalidad se convierta en un asunto de expertos constitucionalistas, pues a mayor exigencia de erudición menos alcance de la institución.

3. Para la Corte Constitucional de Colombia, quien actúe como accionante tendrá que presentar las razones por las cuales la norma demandada contradice la Constitución y exige además la Corte que las razones presentadas por el actor sean claras, ciertas, específicas, pertinentes y suficientes, elementos estos que no hacen parte del Decreto 2067 del 2001 y son establecidos por la Corte por vía jurisprudencial, sobre estos, la misma Corte explica que:

a) La claridad de la demanda es para la Corte Constitucional un requisito indispensable para establecer la conducencia del concepto de la violación y obliga al demandante a seguir un hilo conductor de la argumentación que permita al lector entender el contenido de la demanda y las justificaciones en las que se basa.

b) La certeza significa que la demanda recae sobre una norma jurídica real y existente. El ejercicio de la acción pública de inconstitucionalidad supone la confrontación del texto constitucional con una norma que tiene un contenido verificable a partir de la interpretación de su propio texto.

c) Las razones específicas consisten en la formulación de por lo menos un cargo constitucional concreto contra la norma demandada. Para la Corte Constitucional colombiana el juicio de constitucionalidad se fundamenta en la necesidad de establecer si realmente existe una oposición objetiva y verificable entre el contenido de la norma y el texto de la Constitución Política, resultando inadmisible para ella, que se deba resolver la constitu- 
cionalidad de una norma a partir de argumentos vagos, indeterminados, indirectos, abstractos y globales. Cuando esto no se hace, la Corte ha señalado la ineptitud de la demanda de inconstitucionalidad por inadecuada presentación del concepto de la violación.

d) La pertinencia es, según la Corte Constitucional, un elemento esencial de las razones que se exponen en la demanda de inconstitucionalidad. Lo que significa que el cuestionamiento normativo debe ser de naturaleza constitucional, los preceptos que se buscan salvaguardar están contenidos en la Constitución o hacen parte del bloque de constitucionalidad. Para la Corte son inaceptables los argumentos que se formulan teniendo como referente exclusivamente a la ley por tratarse de un juicio de constitucionalidad y no de legalidad; tampoco prosperarán las acusaciones que fundan el reparo contra la norma demandada en un análisis de conveniencia por tratarse de un juicio de constitucionalidad abstracto y no concreto.

e) La suficiencia de los argumentos del accionante contenidos en la demanda deben al menos crear en la Corte una "duda razonable", la argumentación dada por el accionante debe ser lo suficientemente persuasiva para esta corporación como para iniciar el juicio de constitucionalidad.

Además de lo anterior, el accionante también deberá aportar en el texto de la demanda la razón por la cual la Corte es competente para conocerla.

Tratando de hacer menos gravosos la suma de los requisitos jurisprudenciales para el accionante, en esta misma sentencia, la Corte Constitucional estableció el principio pro actione a favor del actor, que establece que en caso de duda, esta debe resolverse en beneficio del actor y proceder a la admisión de la demanda y al fallo de fondo.

La exigencia de que las razones presentadas por el actor sean claras, ciertas, específicas, pertinentes y suficientes, conforme a los criterios fijados por la Corte para estos conceptos, no han sido fijados ni por el constituyente ni por el legislador, sino por el mismo guardián de la Constitución colombiana, y su excesiva aplicación puede reducir a su mínima expresión la naturaleza de la acción pública de inconstitucionalidad. La misma Corte trata de matizar el alcance limitante de su teoría al afirmar que la consagración de estos requisitos mínimos no puede entenderse, entonces, como una limitación a los derechos políticos del ciudadano, pues lo que quiere la Corte al identificar el contenido de la demanda de inconstitucionalidad es fijar unos elementos que le informen adecuadamente para poder proferir un pronunciamiento de fondo evitando un fallo inhibitorio, pero en la práctica lo que se ha hecho es aumentar la carga argumentativa para el demandante de la norma, limitando así el ejercicio del derecho de acción.

A pesar de lo anterior, después del año 2001 grupos y sectores sociales históricamente marginados han obtenido triunfos relevantes precisamente 
en el ejercicio de acciones públicas de inconstitucionalidad, es el caso de las mujeres y la despenalización del aborto en tres circunstancias específicas ${ }^{47}$ y los derechos que han ido adquiriendo las parejas del mismo sexo por vía jurisprudencial ${ }^{48}$. De lo anterior podemos concluir que después de doscientos años de vida republicana y cien de haberse establecido esta institución, la acción pública de inconstitucionalidad a pesar de sus requisitos procesales, sigue siendo una herramienta idónea para el reconocimiento de derechos y la protección de minorías, frente al actuar de las mayorías parlamentarias y demás sujetos que ostentan el poder.

47 Corte Constitucional de Colombia. Sentencia C-355 del 2006. (M.P. Jaime Araújo Rentería y Clara INÉS VARGAS).

48 Corte Constitucional de Colombia. Sentencias C-075 del 2007 (M.P. Rodrigo Escobar GiL); C-811 del 2007 (m.P. Marco Gerardo Monroy Cabra); C-336 del 2008 (M.P. Clara Inés Vargas Hernández); C-029 del 2009 (M.P. Rodrigo Escobar GiL). 


\section{CONCLUSIONES}

Del presente trabajo, atendiendo a los objetivos planteados en la introducción y al desarrollo del mismo, se pueden extraer las siguientes conclusiones y reflexiones:

1. Aunque en Europa la acción pública de inconstitucionalidad no responde a los cánones de la ortodoxia constitucional, ésta encuentra su legitimidad en la posibilidad ciudadana de actuar directamente como elemento de control de los actos expedidos por los diferentes órganos del Estado y su sometimiento al orden constitucional. Esto es un elemento relevante en la aparición y consolidación de verdaderos sistemas constitucionales, democráticos y participativos de derecho.

2. Del análisis histórico de la acción, podemos entender la evolución de la institución a lo largo del constitucionalismo colombiano de los siglos XIX y XX y el desarrollo jurisprudencial que le han dado, primero la Corte Suprema de Justicia, quien tuvo su tutela hasta 1991, y después la Corte Constitucional de Colombia, para concluir que por vía jurisprudencial ambas corporaciones han limitado la acción pública de inconstitucionalidad y sus potencialidades y han puesto condiciones a los ciudadanos para poder acceder a esta forma de control.

3. Del estudio de la doctrina de la Corte Constitucional de Colombia, se puede concluir que ésta ha venido restándoles a los ciudadanos el acceso efectivo a este derecho político al establecer exigencias por vía jurisprudencial, no contenidas ni en la Constitución, ni en la ley. Muestra de lo anterior es la Sentencia C-1052 del 2001, en la cual la Corte estableció un complejo filtro de procedibilidad en la presentación de estas acciones, alejándola del ciudadano y acercándola sólo a eruditos constitucionalistas; a pesar de esto después del 2001 algunas minorías han alcanzado el reconocimiento de derechos a través de acciones públicas de inconstitucionalidad, lo que confirma la idoneidad y eficacia de esta institución.

4. La acción de inconstitucionalidad en Colombia no cumple funciones territoriales o de protección de minorías parlamentarias, como ocurre en otros países. La acción pública de inconstitucionalidad es un mecanismo especial para reclamar la supremacía efectiva de la Constitución y proteger al individuo y las minorías de las mayorías parlamentarias y demás sujetos que ostentan el poder, de ahí que se concluya que cuando la Corte Constitucional limita el acceso a este derecho, también limita el papel del ciudadano dentro de la estructura del poder público y debilita el sistema democrático y participativo en su conjunto. 


\section{BIBLIOGRAFÍA}

María Luisa Balaguer C. El recurso de inconstitucionalidad. Centro de Estudios Políticos y Constitucionales. Madrid. (2001).

Joaquín Brage Camazano. "La acción mexicana de inconstitucionalidad en el marco del derecho comparado: regulación actual y posibles líneas de evolución”. Trabajo publicado en Revista Iberoamericana de Derecho Procesal Constitucional. Proceso y Constitución. núm. 3. Porrúa. México. Enero-junio. (2005).

Mauro Capelletti. ¿Renegar de Montesquieu?: la expansión y legitimidad de la justicia constitucional. En Revista Española de Derecho Constitucional. nº 17. Madrid. (1986).

Eduardo Cifuentes Muñoz. "La jurisdicción constitucional en Colombia”. En La jurisdicción constitucional en Iberoamérica. Edición Dykinson. Madrid. (1997).

Pedro Cruz Villalón. La formación del sistema europeo de control de constitucionalidad (1918-1939). CEC. Madrid. 1987.

Eduardo García de Enterría. La constitución como norma y el tribunal constitucional. Editorial Civitas. Madrid. (1991).

Asunción García Martínez. El recurso de inconstitucionalidad: el proceso directo de inconstitucionalidad. Ed. Trivium S.A. Madrid. (1992).

Laureano Gómez Serrano. El control de constitucionalidad en Colombia: evolución histórica. Ediciones Doctrina y Ley. Bogotá. (2007).

Hans Kelsen. ¿Quién debe ser el defensor de la Constitución? Editorial Tecnos. Madrid. (1993). $3^{\text {a }}$ edición. La primera edición en alemán es de 1929.

"La garantía jurisdiccional de la Constitución". En Escritos sobre la democracia y el socialismo. Ed. Debate. Madrid. (1988).

Karl Loewenstein. Teoría de la Constitución. Editorial Ariel. Barcelona. (1983).

Montesquieu. El espiritu de las leyes. Ed. Orbis S.A. Buenos Aires. (1999).

Javier Pérez Royo. Curso de derecho constitucional. Ed. Marcial Pons. Madrid. (2007).

Carlos Restrepo Piedrahíta. Tres ideas constitucionales. Ed. Universidad Externado de Colombia. Bogotá. (1979).

Francisco Rubio Llorente. "La jurisdicción Constitucional como forma de creación del derecho”. En Revista Española de Derecho Constitucional. Año 8. n 22 . Enero-abril. (1988).

Leopoldo Uprimny. "Verfassungsgerichtsbarkeit in Kolumbien". Estudio presentado al coloquio internacional convocado por el instituto Max Planck para derecho y derecho internacional de extranjeros, incluido en el volumen colectivo Verfassungsgerichtsbarkeit in der Gegenwart. Heidelberg. (1962).

Hernando Valencia Villa. Cartas de batalla: una crítica al constitucionalismo colombiano. Fondo Editorial CEREC. Segunda Edición. Bogotá. (1997).

\section{Constituciones y normas nacionales e internacionales}

Comisión de Estudios Constitucionales. Proyecto de reforma; estudios constitucionales. Tomo II. Bogotá. (1953). 
Constitución Española de 1978.

Constitución Italiana de 1947.

Constitución de la provincia de Santander 1852, Colombia.

Constitución de la República Bolivariana de Venezuela de 1999.

Constitución de la República Bolivariana de Venezuela de 1999. Arts. 334 a 336.

Constitución de la República de Bolivia del 2009. Art. 132.

Constitución de la República de Chile de 1980, reformada en el 2005. Art. 93.

Constitución de la República de Colombia de 1886. Acto Legislativo 3 de 1910. Art. 41.

Constitución de la República de Colombia de 1991.

Constitución de la República de Guatemala de 1985. Art. 267.

Constitución de la República de Honduras de 1982. Art. 184.

Constitución de la República de Nicaragua de 1987. Art. 187.

Constitución de la República de Panamá de 1972. Art. 203.

Constitución de la República del Paraguay de 1992. Art. 260.

Constitución de la República de El Salvador de 1983. Art. 172.

Constitución de la República del Uruguay. Art. 258.

Constitución de la República Federativa del Brasil. Arts. 102 y 103.

Constitución de los Estados Unidos de Colombia de 1863.

Constitución Política del Ecuador 2008. Art. 441.

\section{Corte Constitucional Colombiana}

Sentencia T-002 de 1992.

Sentencia T-614 de 1992.

Sentencia C-003 de 1993.

Sentencia C-275 de 1996.

Sentencia C-536 de 1998.

Sentencia C-608 de 1999.

Sentencia C- 652 del 2001.

Sentencia C-779 del 2001.

Sentencia C-1052 del 2001.

Sentencia C-355 del 2006.

Sentencia C-075 del 2007.

Sentencia C-811 del 2007.

Sentencia C-336 del 2008. 
Sentencia C-029 del 2008.

Corte Suprema de Justicia de Colombia

Gaceta Judicial. Número 155. Año III. Septiembre 28 de 1889.

Sentencia de agosto 28 de 1970.

Sentencia de marzo 4 de 1981.

\section{Cámara de Representantes de Colombia}

Anales de la Cámara de Representantes de Colombia. Bogotá. no 17. Agosto 25, 1894.

Anales de la Cámara de Representantes de Colombia. Bogotá. nº 6. Agosto 13, 1894.

Normas

Ley Fundamental de la República Federal de Alemania. 